\title{
A review of appropriate Endocrine referrals in a District General Hospital
}

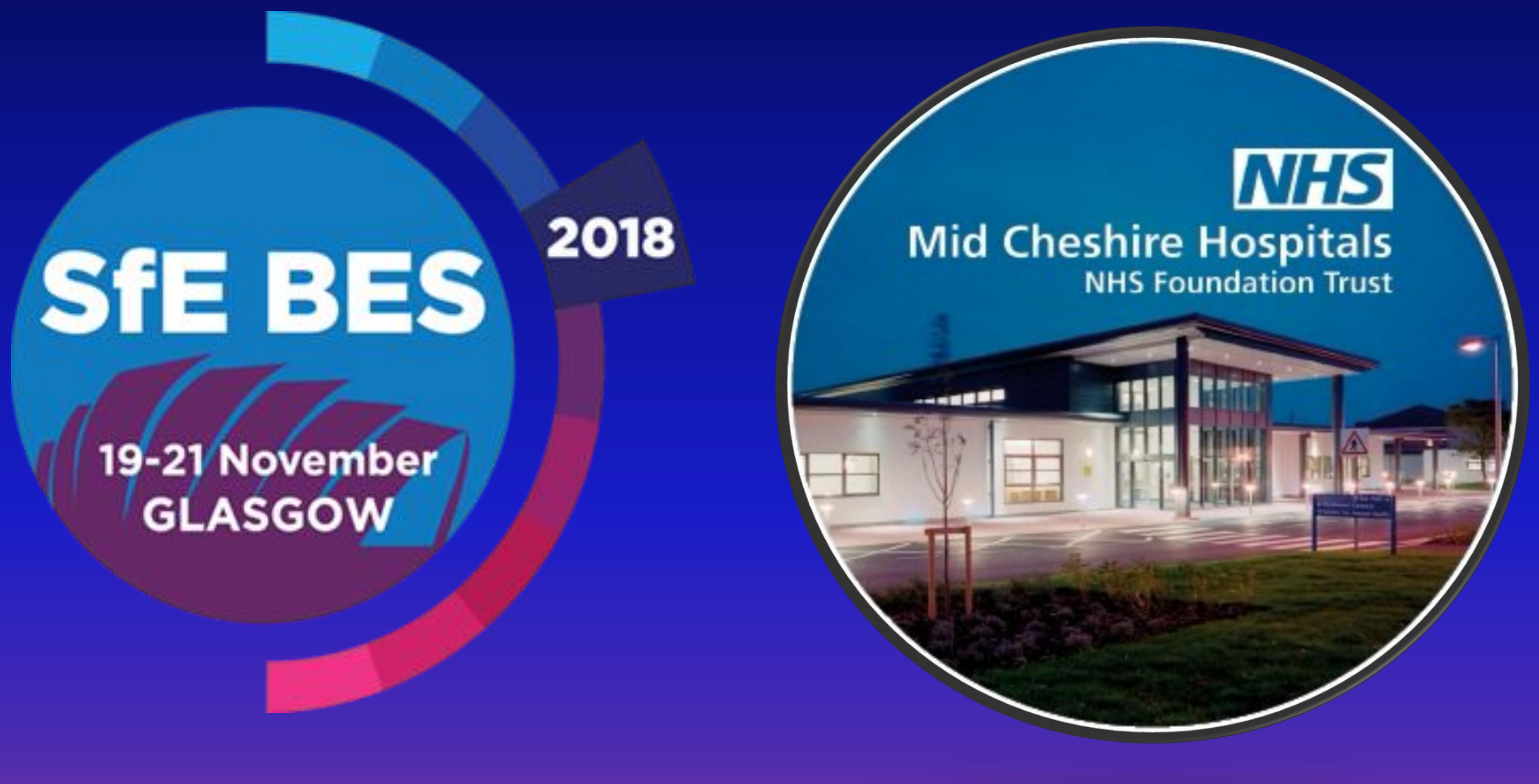

Authors: Yew Wen Yap ${ }^{1}$, Syed Saad Ali Shah¹.

${ }^{1}$ Department of Endocrine and Diabetes, Leighton Hospital, Mid Cheshire Hospitals NHS Foundation Trust. Crewe, United Kingdom.

\section{Background}

Over the last few years, there has been an increase in the demands on the National Health Service, with patients presenting to hospital with multiple comorbidities and increasingly complex needs.

The type of endocrine referrals received can vary both in complexity and also between clinicians. The Royal College of physician has published a 'Referring wisely' report in June 2017 which aims to improve and streamline the quality of referrals received in each speciality ${ }^{1}$.

Two streams of referrals were identified for each speciality, specifically looking at five referrals which were felt to require special attention as identified from the referring speciality and five conditions that should have been within the knowledge of any general physician and therefore should be managed without referrals.

\section{Method}

We retrospectively analysed the inpatient referral caseload over a three month period and matched this to the desired RCP criteria for referrals to review if this had been appropriate ${ }^{1}$.

\begin{tabular}{|c|c|}
\hline $\begin{array}{l}\text { Five most common } \\
\text { referrals requiring } \\
\text { specialist attention: }\end{array}$ & $\begin{array}{l}\text { Five most common } \\
\text { referrals where } \\
\text { knowledge of required } \\
\text { management should be } \\
\text { within the knowledge } \\
\text { domain of all } \\
\text { physicians. }\end{array}$ \\
\hline
\end{tabular}

1. Symptomatic or severe 1. Simple uncomplicated hyponatraemia where hypothyroidism diagnostic doubt exists.

3. Adrenal Insufficiency.

2. Uncomplicated obesity

Sick day rules for steroids for those on long term glucocorticoids

4. Incidentaloma and 4.Acute hypercalcaemia non-incidental masses

(Thyroid/ Adrenal/

Pituitary)

5 Amenorrhoea/

hypogonadism

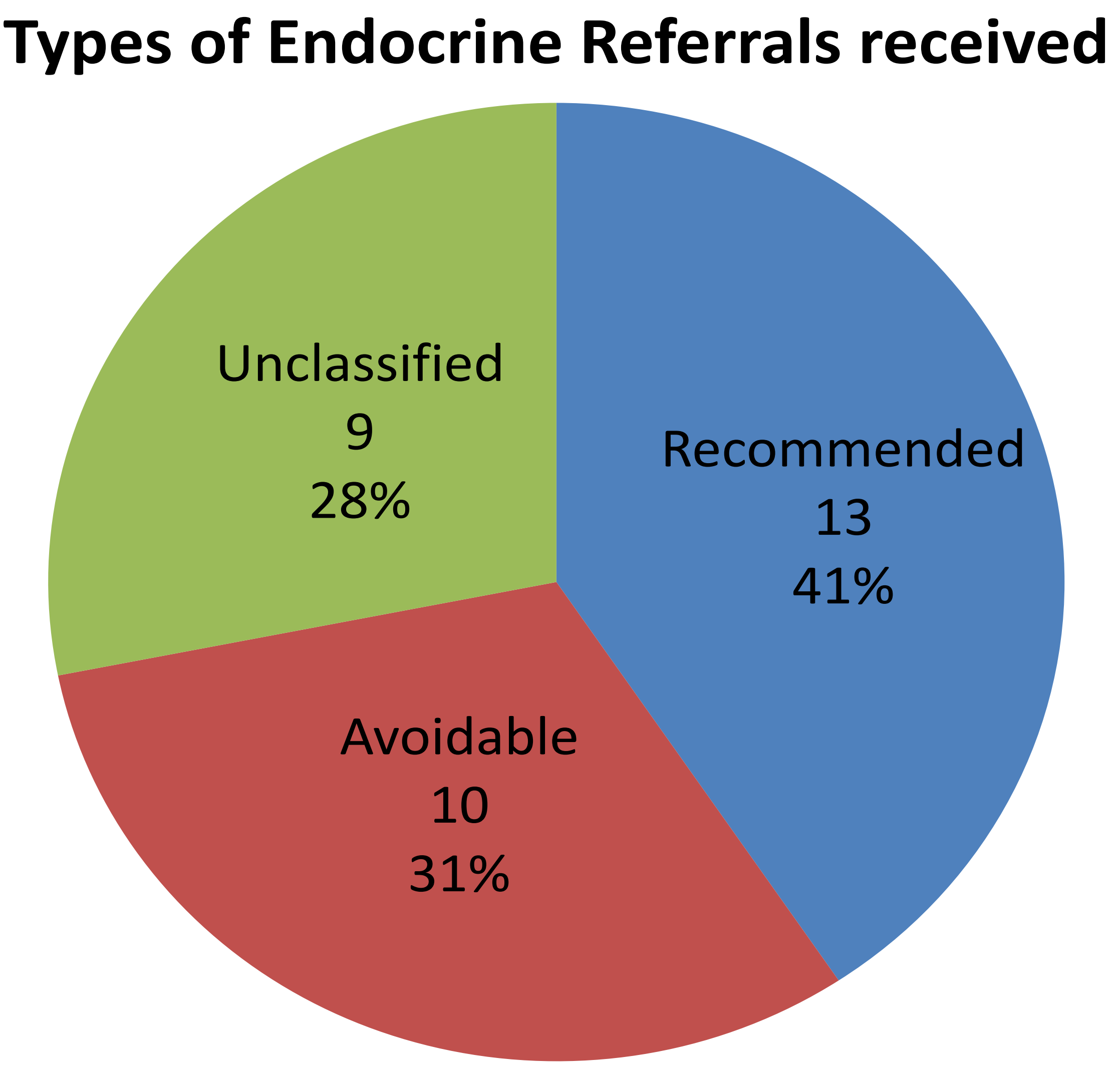

Recommended Referrals Received

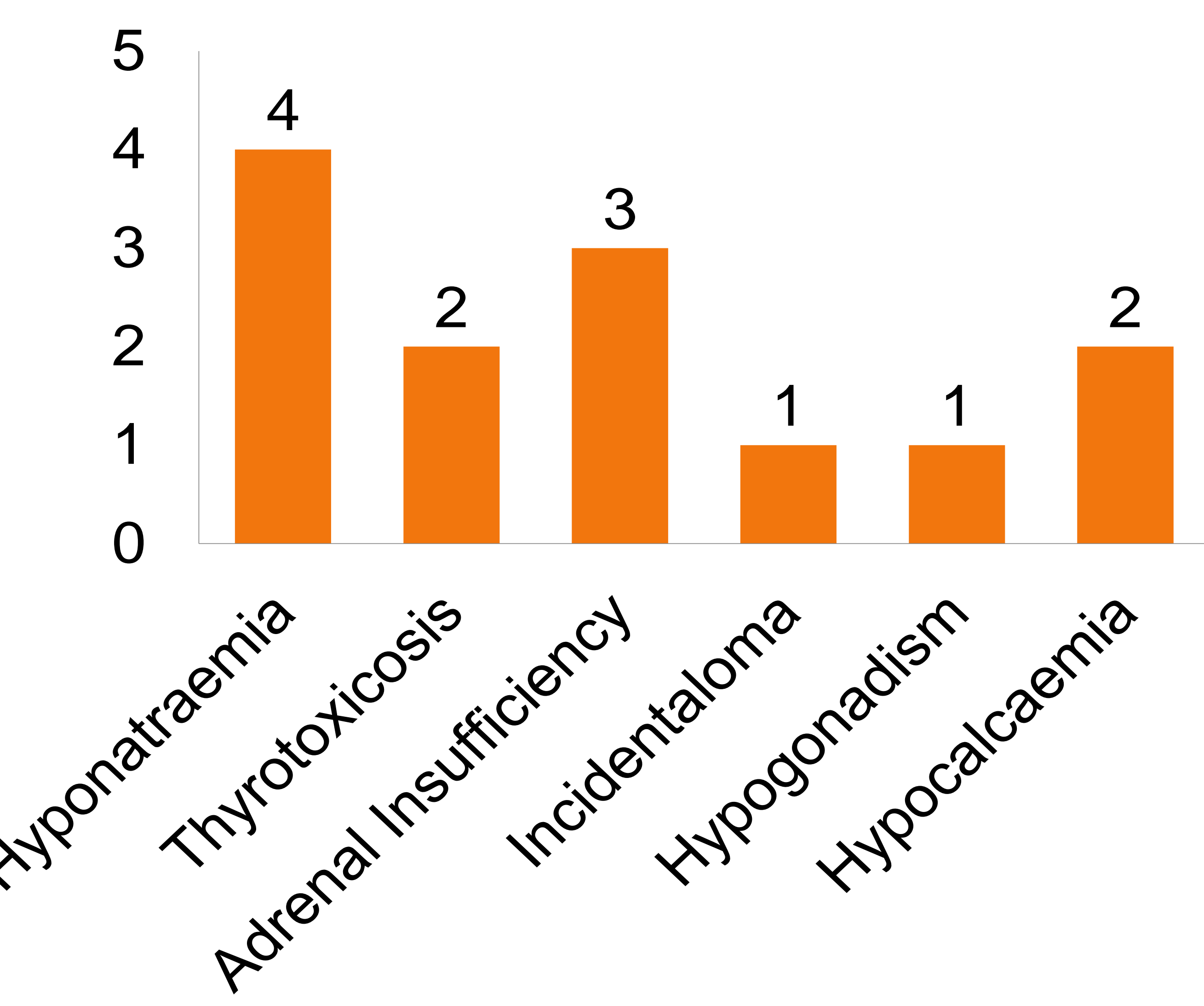

\section{Unclassified Referrals}

During a three month period, 32 patients were referred for an inpatient review. $41 \%$ $(n=13)$ of referrals were in the recommended category of the RCP report. In the recommended referral group, 4 patients had hyponatraemia, 2 for thyrotoxicosis, 3 for adrenal insufficiency, 1 for Incidentaloma, 2 for hypocalcaemia and 1 for amenorrhoea/ hypogonadism.

$31 \%$ of patients $(n=10)$ were in the avoidable referral group, with hypercalcaemia accounting for all of these cases.

9 patients were found to be unclassified in the RCP report accounting for $28 \%$. This included 1 patient for suspected diabetes insipidus, 1 for pituitary insufficiency, 1 for suspected Insulinoma, 3 for hypernatraemia, 1 for weight loss, 1 for subclinical hyperthyroidism and 1 for osteoporosis.

\section{Types of Endocrine Referrals received}

The referrals received by the Endocrinology department reflects the diverse nature of the speciality.

Inpatient referrals adds up to an extra workload on the already stretched Endocrinology service at Leighton Hospital.

We can improve our referral system by following the RCP report 'referring wisely' and help by reducing and streamlining the number of referrals generated, which can potentially be avoided.

At present, there are a number of referrals from the 'avoidable' hypercalcaemia group, prompting a review of the hypercalcaemia guidelines in the trust.

Some of the referrals from unclassified group which we think are appropriate, can be included in the group requiring specialist attention.

We also note that the list is by no means exhaustive and specialists endocrinologists need to work closely with physicians to manage these patients much more effectively.

\section{References:}

1) www.rcplondon.ac.uk/projects/outputs/referring-wisely. 2017. Royal college of physicians. [ONLINE] Available at: https://www.rcplondon.ac.uk/projects/outputs/referring-wisely. [Accessed 21 June 2018]. 2) Royal College of Physicians. Underfunded, underdoctored, overstretched: The NHS in 2016. London: RCP, September2016. www.rcplondon.ac.uk/guidelines-policy/underfunded-underdoctoredoverstretched-nhs-2016[Accessed 3 May 2017]. 